\title{
$t(6 ; 11)$ renal cell carcinoma: a study of seven cases including two with aggressive behavior, and utility of CD68 (PG-M1) in the differential diagnosis with pure epithelioid PEComa/ epithelioid angiomyolipoma
}

Anna Caliò ${ }^{1}$, Matteo Brunelli ${ }^{1}$, Diego Segala ${ }^{2}$, Serena Pedron ${ }^{1}$, Regina Tardanico ${ }^{3}$, Andrea Remo ${ }^{4}$, Stefano Gobbo ${ }^{2}$, Emanuela Meneghelli ${ }^{5}$, Claudio Doglioni ${ }^{6}$, Ondrej Hes ${ }^{7}$, Claudia Zampini ${ }^{1}$, Pedram Argani ${ }^{8}$ and Guido Martignoni ${ }^{1,2}$

${ }^{1}$ Department of Diagnostic and Public Health, Section of Pathology, University of Verona, Verona, Italy; ${ }^{2}$ Department of Pathology, Pederzoli Hospital, Peschiera del Garda, Italy; ${ }^{3}$ Department of Pathology, Spedali Civili, Brescia, Italy; ${ }^{4}$ Department of Pathology, Hospital 'Mater Salutis', Legnago, Italy; ${ }^{5}$ Department of Life and Reproduction Sciences, Clinical Biochemistry Laboratory, University of Verona, Verona, Italy;

${ }^{6}$ Department of Pathology, San Raffaele Hospital, Milano, Italy; ${ }^{7}$ Department of Pathology, Charles University Hospital Plzen, Plzen, Czech Republic and ${ }^{8}$ Department of Pathology, Johns Hopkins Medical Institutions, Baltimore, USA

Renal cell carcinomas with $\mathrm{t}(6 ; 11)$ chromosome translocation involving the TFEB gene are indolent neoplasms which often occur in young patients. In this study, we report seven cases of renal cell carcinoma with TFEB rearrangement, two of whom had histologically proven metastasis. Patients (4F, 3M) ranged in age from 19 to 55 years (mean 37). One patient developed paratracheal and pleural metastases 24 months after surgery and died of disease after 46 months; another one recurred with neoplastic nodules in the perinephric fat and pelvic soft tissue. Histologically, either cytological or architectural appearance was peculiar in each case whereas one tumor displayed the typical biphasic morphology. By immunohistochemistry, all tumors labelled for cathepsin $\mathrm{K}$, Melan-A and CD68 (KP1 clone). HMB45 and PAX8 staining were detected in six of seven tumors. All tumors were negative for CD68 (PG-M1 clone), CKAE1-AE3, CK7, CAIX, and AMACR. Seven pure epithelioid PEComa/ epithelioid angiomyolipomas, used as control, were positive for cathepsin $\mathrm{K}$, melanocytic markers, and CD68 (PG-M1 and KP1) and negative for PAX8. Fluorescence in situ hybridization results showed the presence of TFEB gene translocation in all $t(6 ; 11)$ renal cell carcinomas with a high frequency of split TFEB fluorescent signals (mean $74 \%$ ). In the primary and metastatic samples of the two aggressive tumors, increased gene copy number was observed (3-5 fluorescent signals per neoplastic nuclei) with a concomitant increased number of CEP6. Review of the literature revealed older age and larger tumor size as correlating with aggressive behavior in these neoplasms. In conclusion, we present the clinical, morphological and molecular features of seven $t(6 ; 11)$ renal cell carcinomas, two with histologically demonstrated metastasis. We report the high frequency of split signals by FISH in tumors with $t(6 ; 11)$ chromosomal rearrangement and the occurrence of TFEB gene copy number gains in the aggressive cases, analyzing either the primary or metastatic tumor. Finally, we demonstrate the usefulness of CD68 (PG-M1) immunohistochemical staining in distinguishing $t(6 ; 11)$ renal cell carcinoma from pure epithelioid PEComa/epithelioid angiomyolipoma.

Modern Pathology (2018) 31, 474-487; doi:10.1038/modpathol.2017.144; published online 20 October 2017

Correspondence: Professor G Martignoni, MD, Department of Diagnostic and Public Health, University of Verona, Largo L. Scuro 10, Verona 37134, Italy.

E-mail: guido.martignoni@univr.it

Received 2 May 2017; revised 10 September 2017; accepted 11 September 2017; published online 20 October 2017
Renal cell carcinoma with $\mathrm{t}(6 ; 11)$ chromosome translocation is a well-recognized entity classified as a subtype of the microphthalmia transcription factor (MiT) family of tumors, ${ }^{1}$ which also includes the more common Xp11 translocation renal cell carcinoma. Although the initial description was in 
children, ${ }^{2} \mathrm{t}(6,11)$ renal cell carcinoma may occur in adults in the age range of other renal cell carcinomas. It is characterized by indolent clinical behavior with nine reported instances of metastasis among $\sim 60$ cases in the literature. ${ }^{3-10}$ To date, there are no factors to predict which tumors will be aggressive.

Histologically, $\mathrm{t}(6 ; 11)$ renal cell carcinoma has been classically characterized by a distinctive biphasic morphology with larger epithelioid cells and smaller cells clustered around eosinophilic spheres formed by basement membrane material. ${ }^{11}$ However, several reports have shown a broad range of morphology in molecular confirmed $t(6 ; 11)$ renal cell carcinomas. Papillary and tubulocystic architectures, clear cell, and oncocytoma-like features, diffuse hyalinization with thick-walled blood vessels are some of the unusual pathological features described. ${ }^{11}$ The wide spectrum of morphology results in several differential diagnoses including Xp11 translocation renal cell carcinoma, pure epithelioid PEComa/epithelioid angiomyolipoma, and other more common types of renal cell carcinoma. Among them, pure epithelioid PEComa/ epithelioid angiomyolipoma is the most challenging due to the overlapping immunohistochemical expression of cathepsin $\mathrm{K}$ and melanocytic markers, such as HMB45 and Melan-A. ${ }^{12,13}$ In this regard, staining for PAX8 is the most reliable tool, as it is negative in pure epithelioid PEComa/epithelioid angiomyolipoma and positive in $\mathrm{t}(6 ; 11)$ renal cell carcinoma. ${ }^{8}$ Nevertheless, some cases of $t(6 ; 11)$ renal cell carcinoma do not label for PAX8. ${ }^{7,8}$ Of note, CD68 have been demonstrated consistently positive in pure renal epithelioid PEComa/epithelioid angiomyolipomas ${ }^{14}$ but it has been never investigated in $t(6 ; 11)$ renal cell carcinomas. This is of interest because the underlying genetic alteration in the $t(6 ; 11)$ renal cell carcinoma results in upregulation of the TFEB transcription factor, which regulated expression of a broad range of lysosomal proteins, such as cathepsin K and CD68. ${ }^{15}$

In this study, we describe morphological and molecular features of seven $t(6 ; 11)$ renal cell carcinomas, two with histologically demonstrated metastasis. In addition, we have performed a detailed immunohistochemical panel, focusing on CD68 labeling to evaluate its diagnostic utility.

\section{Material and methods}

\section{Patients and samples}

Seven $\mathrm{t}(6 ; 11)$ renal cell carcinomas were retrieved from the files of participating institutions. Two cases (case 2 and case 3) have been previously reported ${ }^{16,17}$ and five unpublished cases have been added. The number of blocks from, which hematoxylin eosin-stained sections were available for each tumor ranged from 1 to 41 (median 8). All slides were reviewed by two authors (AC, GM). For each case the following morphologic features were recorded: solid, nested, tubulocystic and papillary architecture, the presence of pseudocapsule, perivascular hyalinization, necrosis, and psammoma bodies. With respect to cellular features, the presence of small cells around the basement membrane, eosinophilic and clear cytoplasm, nucleolar grade according to ISUP/WHO 2016, and mitotic figures were assessed.

\section{Immunohistochemistry}

Sections from tissue blocks of $t(6 ; 11)$ renal cell carcinomas and pure epithelioid PEComa/epithelioid angiomyolipomas were immunohistochemically stained with the following antibodies: PAX8 (clone BC12, DSB), Cathepsin K (clone 3F9, dilution 1:2000, Abcam), HMB45 (dilution 1:30, Dako), Melan-A (clone A103, dilution 1:50, Novocastra), and CD68 (clone PG-M1, dilution 1:50, Dako and clone KP1, dilution 1:400, Dako). To better define the immunohistochemical panel of $t(6 ; 11)$ renal cell carcinomas, cytokeratin 8-18 (clone 5D3, dilution 1:100, Novocastra), cytokeratin AE1-AE3 (dilution 1:100, Dako), cytokeratin 7 (clone RN7, dilution 1:100, Novocastra), CD10 (clone 56C6, dilution 1:50, Novocastra), alpha-methylacyl-CoA racemase AMACR (clone 13H7, dilution 1:25, Dako), carbonic anhydrase IX (polyclonal rabbit, dilution 1:1000, Abcam) and SMA (clone 1A4, dilution 1:250, Dako) were used. All samples were processed using a sensitive 'Bond Polymer Refine' detection system in an automated Bond immunohistochemistry instrument (Leica Biosystems). The appropriate positive and negative controls were concurrently carried out. Labeling for each marker was recorded as the percentage of positive cells.

\section{Fluorescence in situ hybridization}

Fluorescence in situ hybridization (FISH) was carried out on the seven tumors and the 37 control cases (10 clear cell renal cell carcinomas, 10 papillary renal cell carcinomas, 5 chromophobe renal cell carcinomas, 5 oncocytomas and 7 pure epithelioid PEComa/epithelioid angiomyolipomas) using dual color break apart TFEB probe (Cytotest Inc, Rockville, MD, USA). Centromeric alpha-satellite specific for chromosome 6 (CEP6) was used as control probes (Vysis-Abbott, Olympus, Rome, Italy) on serial tissue sections. Briefly, $3 \mu \mathrm{m}$ sections were cut from formalin-fixed paraffin-embedded tissue blocks and mounted on positively charged slides. The slides were dried for one hour at $60^{\circ} \mathrm{C}$ then deparaffinized, rehydrated, and fixed in methanol/acetic acid 3:1 for $5 \mathrm{~min}$. Pretreatment was performed at $85^{\circ} \mathrm{C}$ for $30 \mathrm{~min}$ with 0,1 citrate buffer (pH6) solution followed by pepsin ( $4 \mathrm{mg} / \mathrm{ml}$ in $0.9 \% \mathrm{NaCl}, \mathrm{pH} 1.5$ ) treatment for $8 \mathrm{~min}$ at $37^{\circ} \mathrm{C}$. After washing and dehydration, $10 \mu \mathrm{l}$ probe was applied on selected area and sealed with rubber cement. Denaturation was assessed by incubating the slides at $80^{\circ} \mathrm{C}$ for $10 \mathrm{~min}$ in a humidified atmosphere (Thermobrite System) followed by hybridization overnight at $37^{\circ} \mathrm{C}$. The rubber cement and the cover 
Table 1 Clinical and pathological features of TFEB translocation renal cell carcinomas

\begin{tabular}{lllclll}
\hline Case & Age & Gender & Size/Laterality & Stage TNM & Surgery & Follow up \\
\hline 1 & 19 & $\mathrm{~F}$ & $5.5 \mathrm{~cm} / \mathrm{L}$ & pT1bNxMx & Partial nephrectomy & 2 months alive \\
2 & 54 & $\mathrm{~F}$ & $7 \mathrm{~cm} / \mathrm{R}$ & pT1bNxMx & Radical nephrectomy & 36 months alive \\
3 & 20 & $\mathrm{~F}$ & $9.5 \mathrm{~cm} / \mathrm{R}$ & pT2aNxMx & Radical nephrectomy & 36 months alive \\
4 & 55 & $\mathrm{M}$ & $3 \mathrm{~cm} / \mathrm{R}$ & pT1aNxMx & Partial nephrectomy & 78 months alive \\
5 & 34 & $\mathrm{M}$ & $7 \mathrm{~cm} / \mathrm{L}$ & pT1bNxMx & Partial nephrectomy & 30 months alive \\
6 & 42 & $\mathrm{~F}$ & $10 \mathrm{~cm} / \mathrm{L}$ & pT3aN0M1 & Radical nephrectomy & Metastasis after 24 months, dead after 46 months \\
7 & 33 & $\mathrm{M}$ & $8 \mathrm{~cm} / \mathrm{L}$ & pT3aNxM1 & Radical nephrectomy & Perinephric nodules after 24 months, 48 months alive \\
\hline
\end{tabular}

Abbreviations: F: female, M: male, R: right, L: left.

slip were removed and the slides were washed in $2 \times$ $\mathrm{SSC} / 0.3 \% \mathrm{NP} 40$ for $15 \mathrm{~min}$ at room temperature and then at $72{ }^{\circ} \mathrm{C}$ for $2 \mathrm{~min}$. Next, the tissue sections were counterstained with DAPI antifade (Prolong Gold Antifade Reagent Life Technologies) and examined under an $\times 60$ to $\times 100$ oil immersion objective using an Olympus BX61 fluorescence microscope equipped with filters that visualize the different wavelengths of the fluorescent probe.

Scoring was performed by two experienced pathologists (AC and $\mathrm{MB}$ ). At least 100 neoplastic nonoverlapping nuclei were included in the scoring. To avoid false-positive results due to nuclear truncation, cells with a single fluorescent signal were not evaluated.

\section{Cytogenetic analysis}

Cells were cultured with in situ method (cover glass in a $35 \mathrm{~mm}$ Petri dish) and RPMI 1640 medium 20\% FBS and collected following standard cytogenetic techniques. Briefly, each dish was examined daily after the fourth day for growth and the rate of proliferation. When cultures were ready the cells were exposed to colcemid $(0.01 \mathrm{mg} / \mathrm{ml})$ for $15 \mathrm{~h}$ (overnight), hypotonic treatment $(0.1 \%$ sodium citrate), and fixative solution (Carnoy). Karyotype was studied in QFQ banding (quinacrine dihydrochloride $500 \mathrm{mg} / 100 \mathrm{ml}$ ) by fluorescence microscopy. FISH was performed using TUPLE1 probe (Cytocell) following the manufacturer protocol.

\section{Statistical analysis}

Fisher's exact test was used to compare categorical data for clinical and pathological characteristics and Student's $t$-test to compare continuous data. All $P$ values are based on a two-tailed hypothesis. The results were considered statistically significant if the $P$-value was $<0.05$.

\section{Results}

\section{Clinical characteristics}

The clinical features of the 7 patients are detailed in Table 1. Four patients were female and three male (F:
M ratio, 1.3:1). The patients' ages at diagnosis ranged from 19 to 55 years (mean 37, median 38). One patient (case 5) had history of non Hodgkin lymphoma treated with chemotherapy and a biopsy was performed when the renal mass was discovered. In case 1, a diagnosis suggesting oncocytoma was made in a core biopsy sample from different institution. Follow up was available for all patients, ranging from 2 to 78 months (mean 39, median 41). Two of them developed metastasis: patient 6 showed paratracheal and pleural metastasis 24 months after the surgery and died of disease after 46 months; patient 7 recurred with nodules in the perinephric fat and pelvic soft tissue after 24 months and he was alive 48 months after the radical nephrectomy.

\section{Pathological features}

The tumors ranged in size from 3 to $9.5 \mathrm{~cm}$ (mean 7.4, median 7.5; Figure 1a). All but one was solid and tan mass (Figure 1b), the smallest tumor was solid and cystic (Figure 1c and d). Grossly, in the cases treated by radical nephrectomy, renal vein invasion was not identified. The histological features are described separately for completeness.

Case 1. A discontinuous thick pseudocapsule with dystrophic calcification was present. The tumor was composed of epithelioid cells with eosinophilic and focally clear cytoplasm and small nucleoli (G2 by ISUP/WHO 2016) mainly arranged in solid-alveolar architecture (Figure 2a). Areas with tubular and microcystic pattern were seen. Neither necrosis nor mitotic activity was found ( $<1$ per $10 \mathrm{HPF}$ ).

Case 2. A discontinuous pseudocapsule was present. The neoplasm was mainly composed of nests and tubules of polygonal cells with well-defined cell borders, clear cytoplasm, and central round nuclei with prominent nucleoli (G3 by ISUP/WHO 2016). Additional areas showing cells with granular and eosinophilic cytoplasm were present. Tubular and micropapillary structures were also observed. Smaller cells with dark nuclei clustering around hyaline material were focally seen. Mitotic figures were occasionally encountered ( $0-1$ per $10 \mathrm{HPF})$. No necrosis was found. 

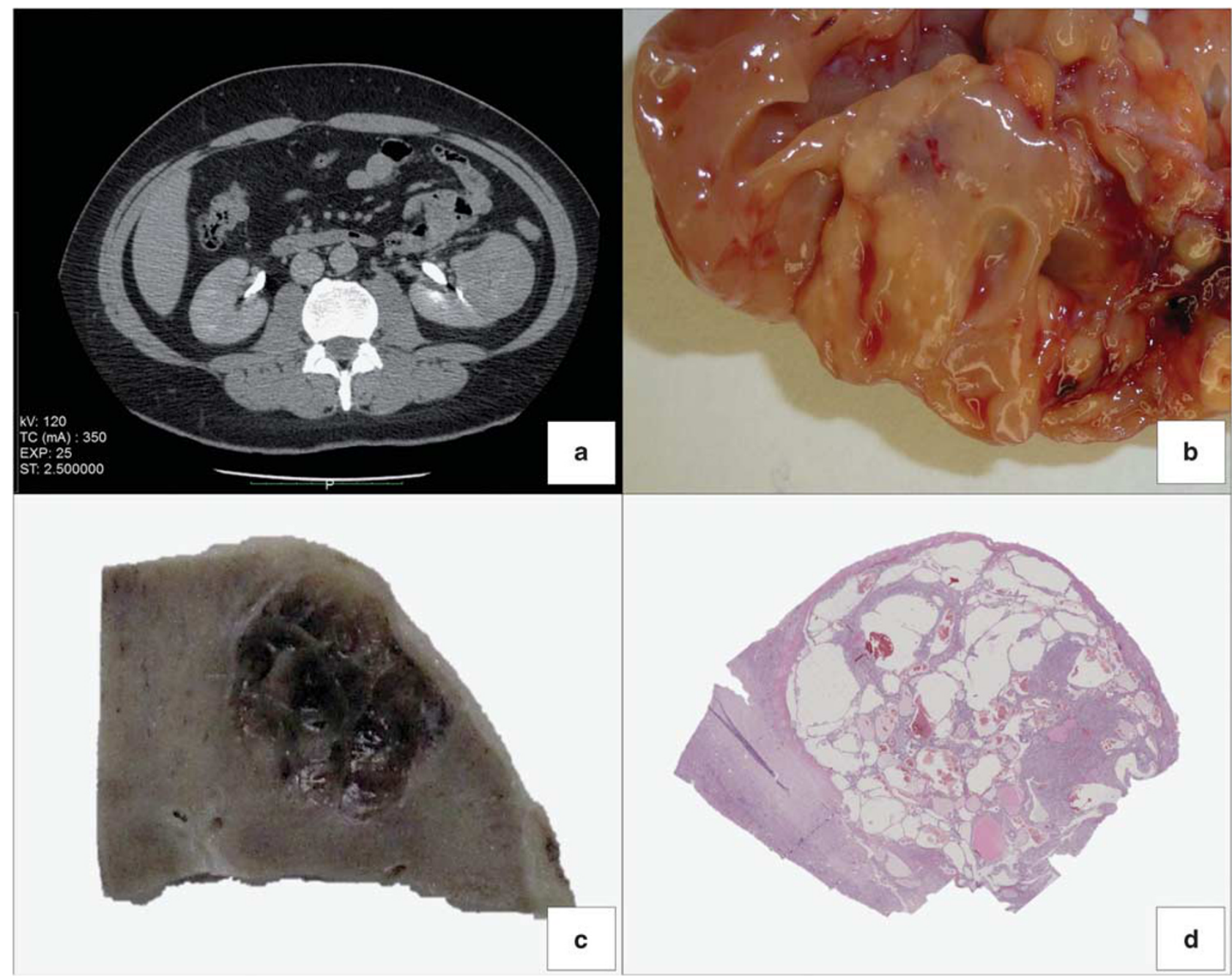

Figure 1 The most common macroscopic appearance of t(6;11) renal cell carcinoma: a solid (a) and tan mass (b). Only one tumor displayed a solid and cystic architecture (c, d).

Case 3. The tumor was partially circumscribed by a fibrous pseudocapsule and made up of granular eosinophilic polygonal cells with conspicuous nucleoli (G2 by ISUP/WHO 2016) arranged in solid and solid/alveolar architecture. At low power magnification, smaller lymphocyte-like cells grouped around collagenous spherules formed by basement membrane material were easily observed. Additional areas with microcysts were focally present. A few psammoma bodies and 1 mitotic figure per $10 \mathrm{HPF}$ were found. No necrosis was observed.

Case 4. The tumor was solid and cystic and well delineated by a pseudocapsule. The cells lining the cysts showed abundant vacuolated clear and eosinophilic cytoplasm with round nuclei and pinpoint nucleoli (G2 by ISUP/WHO 2016). Brownish pigment and psammoma bodies were extensively present. Mitotic figures were occasionally seen (0-1 per $10 \mathrm{HPF}$ ). Necrosis was absent.
Case 5. The biopsy showed an epithelial neoplasm made up of sheets of small cells with round hyperchromatic nuclei and eosinophilic cytoplasm. In the resected specimen, the tumor consisted of a mixture of epithelioid cells with clear and granular eosinophilic cytoplasm and indistinct nucleoli (G2 by ISUP/WHO 2016; Figure 2b and c). Architecturally, solid areas, microcystic and papillary changes (Figure 2d and e) and bony metaplasia were observed. Areas of hyalinized stroma with calcification and hyalinized vessels were present (Figure 2f). Mitotic figures were occasionally seen (1 per 10 HPF). No necrosis was observed.

\section{Case 6}

Primary tumor. The tumor showed pushing margins and it was partially delineated from renal parenchyma by a pseudocapsule. However, an infiltrative growth pattern in the perinephric fat was focally present. The neoplastic cells were large and epithelioid with abundant clear cytoplasm 


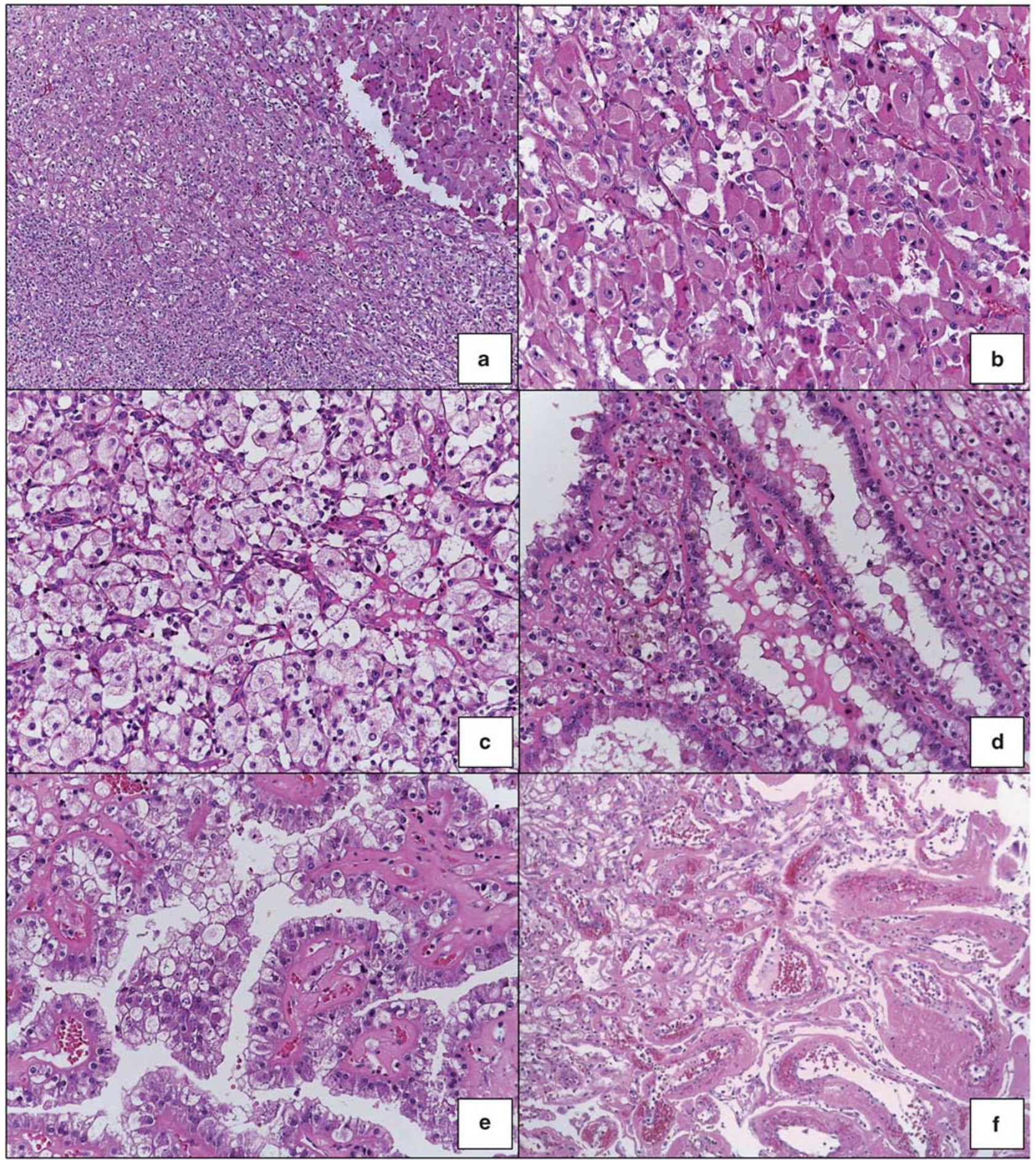

Figure 2 Different histologic appearances of t(6;11) renal cell carcinoma. Large epithelioid eosinophilic (a, b) and clear cells. (c) Areas with microcystic (d) and papillary (e) pattern. Hyaline sclerosis with eosinophilic material around vessels, a pattern reminiscent of epithelioid angiomyolipoma (f).

and enlarged hyperchromatic nucleoli (G3 by ISUP/ WHO 2016) (Figure 3a). Hyaline sclerosis with eosinophilic material around vessels, dystrophic calcification and bony metaplasia were present throughout the tumor. Minimal mitotic activity was encountered $(<1$ per $10 \mathrm{HPF})$ in most of the neoplasm. Focal necrosis was seen (Figure 3b). An additional area of neoplastic overgrowth was found. This area measured roughly $1.5 \mathrm{~cm}$ and was characterized by small eosinophilic cells (G3 by ISUP/ WHO 2016) with necrosis and higher mitotic activity (15 per $10 \mathrm{HPF}$ ). Eight hilar lymph nodes were examined and were negative for tumor metastasis. 


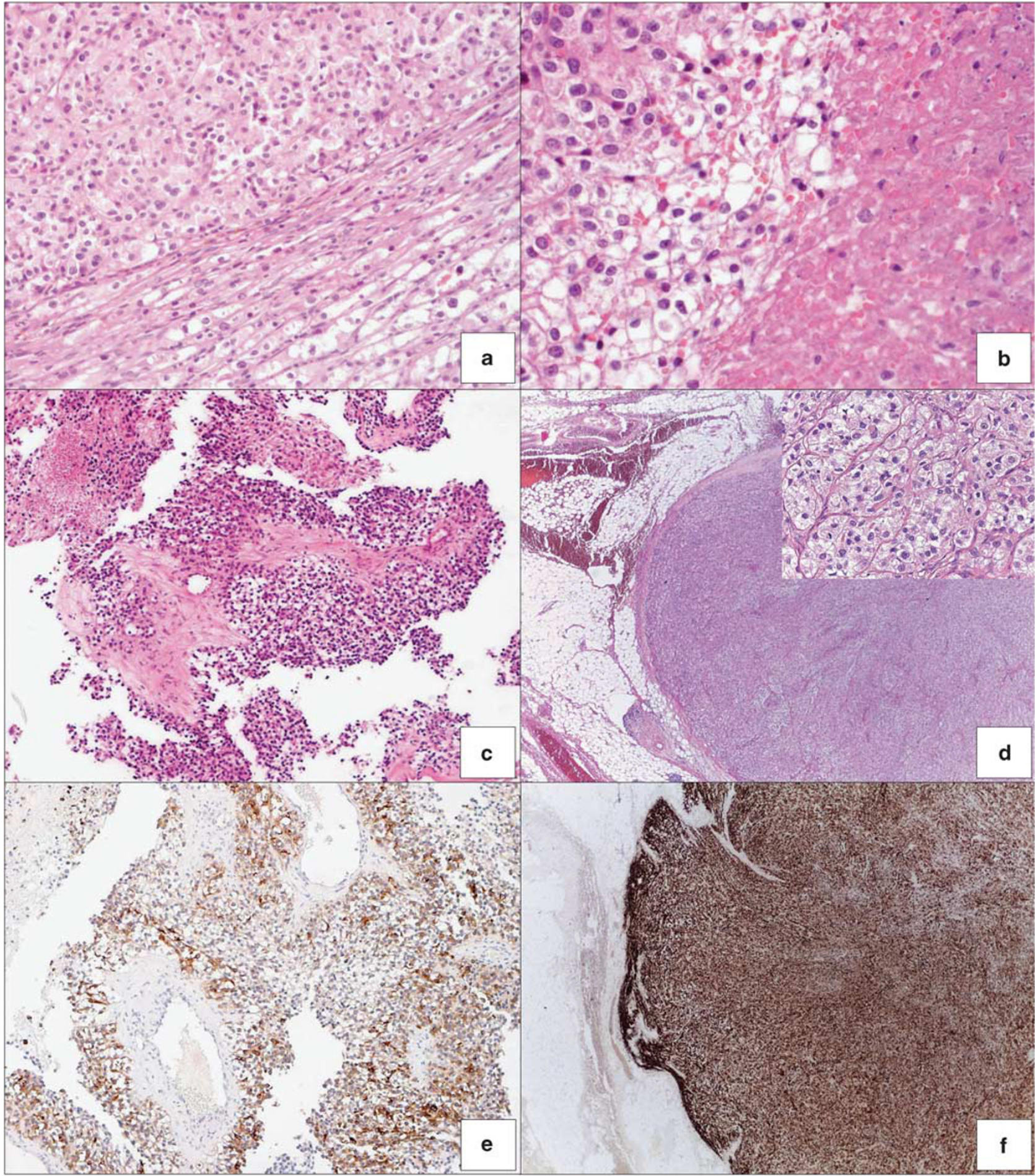

Figure $3 \mathrm{t}(6 ; 11)$ renal cell carcinomas with aggressive behavior. The broad and epithelioid clear cells of case 6 (a) with focal necrosis (b). A biopsy of pleura showing clear cell with distinct borders and small round nuclei (c). Nodules in perinephric fat displayed a solidalveolar pattern, note the clear to eosinophilic epithelioid cells (insert) (d). Expression of Melan-A (e) and cathepsin K (f) in tumor metastasis.

Metastatic tumor. Biopsy material of pleural metastasis was available for histological characterization and consisted of clear cells with distinct borders and small round nuclei (Figure 3c). No necrosis or mitotic activity was observed.
Case 7

Primary tumor. The tumor was characterized by cells with clear to eosinophilic cytoplasm and small nuclei (G2 by ISUP/WHO 2016) arranged in solidalveolar pattern and focal papillary architecture. 
Table 2 Immunohistochemical results of TFEB translocation renal cell carcinomas

\begin{tabular}{|c|c|c|c|c|c|c|c|c|c|c|c|c|c|}
\hline Case & $P A X 8$ & Cathepsin K & $H M B 45$ & MelanA & $C D 68$ (PG-M1) & $C D 68(K P 1)$ & $A E 1 A E 3$ & $C K 8-18$ & CD10 & $C A I X$ & $A M A C R$ & $C K 7$ & $S M A$ \\
\hline 1 & $80 \%+$ & $100 \%+$ & $5 \%+$ & $80 \%+$ & neg & $60 \%+$ & neg & $15 \%+$ & $10 \%+$ & neg & neg & neg & neg \\
\hline 2 & $80 \%+$ & $70 \%+$ & $5 \%+$ & $80 \%+$ & neg & $50 \%+$ & neg & $30 \%+$ & neg & neg & neg & neg & neg \\
\hline 3 & $10 \%+$ & $70 \%+$ & $5 \%+$ & $20 \%+$ & neg & $5 \%+$ & neg & $70 \%+$ & neg & neg & neg & neg & neg \\
\hline 4 & $70 \%+$ & $100 \%+$ & $5 \%+$ & $80 \%+$ & neg & $50 \%+$ & neg & $30 \%+$ & $10 \%+$ & neg & neg & neg & neg \\
\hline 5 & $60 \%+$ & $90 \%+$ & $5 \%+$ & $80 \%+$ & neg & $50 \%+$ & neg & $10 \%+$ & neg & neg & neg & neg & neg \\
\hline 6 & $20 \%+$ & $80 \%+$ & $10 \%+$ & $80 \%+$ & neg & $60 \%+$ & neg & $5 \%+$ & $5 \%+$ & neg & neg & neg & neg \\
\hline Metastasis & $10 \%+$ & $80 \%+$ & $5 \%+$ & $80 \%+$ & neg & $40 \%+$ & neg & $5 \%+$ & $10 \%+$ & neg & neg & neg & neg \\
\hline 7 & neg & $100 \%+$ & neg & $5 \%+$ & neg & $50 \%+$ & $<5 \%+$ & $10 \%+$ & neg & neg & neg & neg & neg \\
\hline Metastasis & neg & $100 \%+$ & neg & $5 \%+$ & neg & $50 \%+$ & $<5 \%+$ & $10 \%+$ & neg & neg & neg & neg & neg \\
\hline
\end{tabular}

Abbreviations: CAIX: carbonic anhydrase IX, AMACR: alpha-methylacyl-CoA racemase.

A few mitotic figures were encountered (3 per 10 HPF). Necrosis was absent.

Metastatic tumor. The same features were observed in metastatic nodules in perinephric fat and pelvis (Figure 3d). Higher mitotic activity was found (5 per $10 \mathrm{HPF})$.

\section{Immunohistochemical features}

The immunohistochemical results are tabulated in Table 2. All $\mathrm{t}(6 ; 11)$ renal cell carcinomas were diffusely positive for cathepsin K and CD68 (KP1 clone) whereas expression for Melan-A and CK8-18 was observed in all tumors with different percentages (Figure $3 \mathrm{e}$ and f). Staining for PAX8 and HMB45 was found in six of seven tumors. Three tumors showed focal expression of CD10. Cytokeratin AE1AE3, CK7, CD68 (PG-M1 clone), CAIX, AMACR, and SMA were negative in all cases (Figure 4a,c,e,g) with the exception of case 7 in which focal $(<5 \%)$ cells displayed cytokeratin AE1AE3 immunoreactivity. In the overgrowth area of case 1, the immunohistochemical expression of the markers was the same.

All seven pure epithelioid PEComa/epithelioid angiomyolipomas labeled for cathepsin $\mathrm{K}$, melanocytic markers (HMB45 and Melan-A) and CD68 (both PG-M1 and KP1 clones) and were negative for PAX8 (Table 3 and Figure 4b,d,f,h). Staining for SMA was detected in 4 of 7 tumors.

\section{FISH results}

All seven $t(6 ; 11)$ renal cell carcinomas and two metastasis demonstrated a high frequency of split TFEB fluorescent signals (Figure 5a) ranging from 61 to $94 \%$ (mean $74 \%$, median $75 \%$ ) detailed in Table 3. In all these samples the distance of red and green signals was greater than twice signal diameter. In two tumors (case 6 and 7) increased gene copy number was observed (3-5 fluorescent signals per neoplastic nuclei) (Figure 5b). In case 6, the increased number of fluorescent signals was mainly observed in the overgrowth nodule. Both tumors showed increased number of CEP6 (3-4 copies) whereas the remaining four tumors were disomic. None of the 37 control tumors showed split TFEB fluorescent signals. Minimally split fluorescent signals in which fluorescent signals were separated by a signal diameter were occasionally observed (mean 3.8\%, median 3\%, range from 0 to $10 \%)$; these were considered artifactual and no significant.

\section{Cytogenetic results}

Fresh tumor samples were available for karyotype analysis in 2 of 7 tumors (case 2 and case 5). The karyotype result of case 2 was previously reported. ${ }^{16}$ In case 5 , all the analyzed cells showed the translocation $\mathrm{t}(6 ; 11)(\mathrm{p} 21 ; \mathrm{q} 12)$ (Figure 5c). A subset of these cells, about $20 \%$, showed additional rearrangements including monosomy of chromosome 22 and translocation of almost its entire long arm on the short arm of chromosome 8, as showed by FISH results in which both the probes mapping in 22 q11.2 and q13.3 are located on the rearranged chromosome 8.

\section{Literature review and comparison of aggressive and non-aggressive $\mathbf{t}(6 ; 11)$ renal cell carcinoma}

Aggressive t $(6 ; 11)$ renal cell carcinoma. The results of the literature review ${ }^{3-10}$ and the new two aggressive cases of $t(6 ; 11)$ renal cell carcinoma are summarized in Table 4 . The mean age of these patients was 46 years and the median 42 years (range from 33 to 77$)$. There was a male predominance ( $8 \mathrm{M}$, 3 F), with a male-to-female ratio of roughly $2.6: 1$. The tumors' size ranged from 3 to $27 \mathrm{~cm}$ (mean 12, median 10). Follow up for these cases ranged from 3 to 120 months (mean 59, median 48). Among the eleven patients, four died for disease. All of them developed metastasis. In decreasing order of frequency, the metastatic sites were lung (3 cases), bone (3 cases), liver (2 cases), lymph nodes (2 cases), perinephric fat and pelvic soft tissue (1 case), vagina ( 1 case). In one patient, the site of metastasis was not specified. 


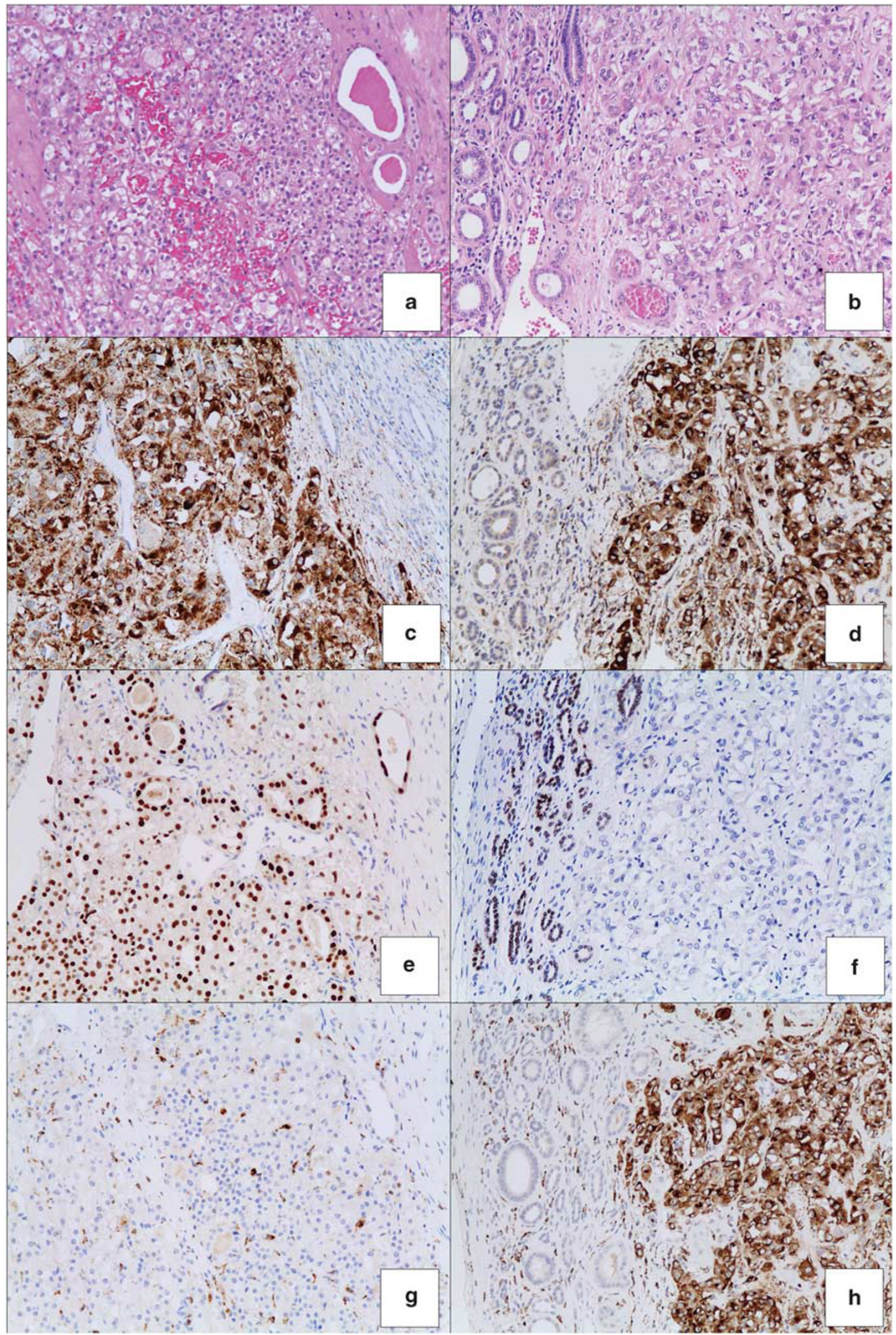

Figure 4 t(6;11) renal cell carcinoma (a) showing cathepsin K (c) and PAX8 (e) positivity and CD68 PG-M1 negativity (g). Pure epithelioid PEComa/epithelioid angiomyolipoma (b) expressing cathepsin $\mathrm{K}(\mathbf{d})$. On the contrary of $\mathrm{t}(6 ; 11)$ renal cell carcinoma, pure epithelioid PEComa/epithelioid angiomyolipoma was negative for PAX8 (f) but positive for CD68 PG-M1(h). 
Table 3 Comparison of immunohistochemical and FISH results of TFEB translocation RCCs and epithelioid angiomyolipoma

\begin{tabular}{|c|c|c|c|c|c|c|c|}
\hline Case & Average TFEB split signals by FISH & $P A X 8$ & CD68(PG-M1) & Cathepsin $K$ & $H M B 45$ & Melan- $A$ & $S M A$ \\
\hline \multicolumn{8}{|c|}{$t(6 ; 11) R C C$} \\
\hline 1 & $74 \%$ & + & neg & + & + & + & neg \\
\hline 2 & $80 \%$ & + & neg & + & + & + & neg \\
\hline 3 & $75 \%$ & + & neg & + & + & + & neg \\
\hline 4 & $65 \%$ & + & neg & + & + & + & neg \\
\hline 5 & $78 \%$ & + & neg & + & + & + & neg \\
\hline $6^{\mathrm{a}}$ & $94 \%$ & + & neg & + & + & + & neg \\
\hline $7^{\mathrm{a}}$ & $61 \%$ & neg & neg & + & neg & + & neg \\
\hline \multicolumn{8}{|c|}{ Epithelioid angiomyolipoma/epithelioid PEComa } \\
\hline I & $0 \%$ & neg & + & + & + & + & + \\
\hline II & $0 \%$ & neg & + & + & + & + & neg \\
\hline III & $0 \%$ & neg & + & + & + & + & + \\
\hline IV & $0 \%$ & neg & + & + & + & + & neg \\
\hline V & $0 \%$ & neg & + & + & + & + & + \\
\hline VI & $0 \%$ & neg & + & + & + & + & + \\
\hline VII & $0 \%$ & neg & + & + & + & + & neg \\
\hline
\end{tabular}

a Primary tumor.

Non-aggressive t(6;11) renal cell carcinoma. The new cases of $\mathrm{t}(6 ; 11)$ renal cell carcinoma and the results of the literature review ${ }^{2,3,5-8,10,12,16-30}$ are presented in Table 5 . Overall, 53 cases of $\mathrm{t}(6 ; 11)$ renal cell carcinoma were found. The mean age of these patients was 30 years and the median 29 years (range from 3 to 68). There was no gender predominance $(26 \mathrm{M}, 25 \mathrm{~F})$. The tumors' size ranged from 1 to $19 \mathrm{~cm}$ (mean and median 7). When follow up was available, it ranged from 2 to 60 months (mean 27 and median 25).

Comparison of aggressive and non-aggressive t(6;11) renal cell carcinoma. There is a statistically significant difference in age and tumors' size between aggressive and non-aggressive tumors. The aggressive tumors occur in older patients $(P=0.007)$ and tend to be larger $(P=0.04)$. Although there is a prevalence of aggressive $t(6 ; 11)$ renal cell carcinoma in men, no significant difference in gender was found $(P=0.32)$.

\section{Discussion}

Most instances of $\mathrm{t}(6 ; 11)$ renal cell carcinoma have an indolent clinical course with a few published cases demonstrating aggressive behavior. ${ }^{3-10}$ In this study, we reported 2 patients with $\mathrm{t}(6 ; 11)$ renal cell carcinoma who both developed metastasis after 24 months. In both cases, we histologically confirmed the metastasis and FISH assay was performed in primary and metastatic samples. In our review of the literature, we have identified nine $\mathrm{t}(6 ; 11)$ renal cell carcinomas with aggressive behavior. Among them, in 2 tumors no molecular analysis for the presence of translocation $(6 ; 11)$ was carried out, ${ }^{3,4}$ in the remaining karyotyping or FISH assay have revealed TFEB rearrangement. However, the recurrences have been usually reported as only a clinical finding. In only one case, lung metastasis was histologically examined and the presence of $t(6 ; 11)$ (p21.1;q12 13) chromosomal rearrangement was demonstrated; that patient had a renal tumor diagnosed as 'clear cell renal cell carcinoma' 8 years before which was not reevaluated for the presence of translocation. ${ }^{6}$ Interestingly, we also reported an increasing number of TFEB fluorescent signals (3-5 signals) in the two aggressive cases of our series. This drew our attention since TFEB amplified renal cell carcinoma has been recently described. ${ }^{10,31,32}$ Hence, we investigated the possibility of TFEB amplification and FISH analysis with a chromosome 6 centromeric probe. After the correction by chromosome 6 centromeric probe, we observed a similar increased number of TFEB and CEP6 fluorescent signals; therefore, we did not consider them as amplified tumors. Nevertheless, the occurrence of TFEB gene copy number gains is particularly interesting since both TFEB amplification and rearrangement have been demonstrated in two previously published primary tumors. ${ }^{7,10}$ It is worth noting that Peckova et al. reported the presence of amplification without any additional details whereas Argani et al. defined amplification as $>10: 1$ ratio of TFEB fluorescent signal to centromeric probe. This aspect is fascinating because it is possible that increasing in copy number of TFEB gene region in $\mathrm{t}(6 ; 11)$ renal cell carcinoma may predict an aggressive clinical course. In this light, we may speculate that the occurrence of TFEB gene copy number gains in our two aggressive cases might be the result of genomic instability. However, further investigations of larger series should be conducted to validate this result.

Overall, $\mathrm{t}(6 ; 11)$ renal cell carcinomas described in this article occurred in patients around 40 years, the tumors' size was $7.5 \mathrm{~cm}$ without a typical gross appearance (6 of 7 tumors were solid and one tumor extensively cystic). Interestingly, one patient (case 5) was previously treated with chemotherapy for the 

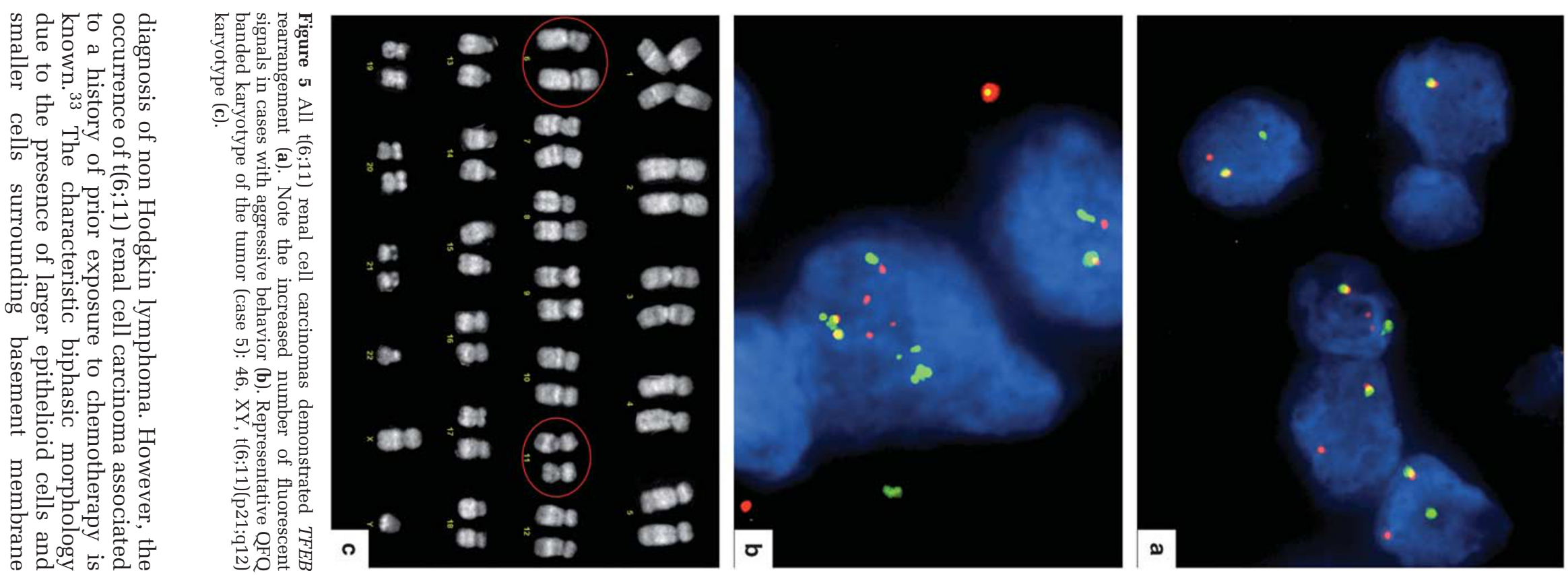

Table 4 Aggressive t(6;11) renal cell carcinomas

\begin{tabular}{|c|c|c|c|c|c|c|c|c|}
\hline Case & References & Age & Gender & Size $(\mathrm{cm})$ & Stage TNM & Karyotype/FISH & Follow up & Notes \\
\hline 1 & Camparo et al. ${ }^{3}$ & 36 & M & 20 & pT3bN2M1 & $\mathrm{NA}^{\mathrm{a}}$ & Dead after 3 months & Multiple metastasis \\
\hline 2 & Ishihara et al. ${ }^{4}$ & 45 & $\mathrm{M}$ & 7 & pT3aN1M1 & NA & 7 months alive & Lung and vertebral metastasis \\
\hline 3 & Argani et al. ${ }^{5}$ & 42 & $\mathrm{M}$ & 27 & pT3NxM1 & break apart probe & NA & Liver metastasis \\
\hline 4 & Argani et al. ${ }^{5}$ & 60 & $\mathrm{M}$ & 14 & pT3bNoM1 & break apart probe & NA & Liver metastasis+IVC thrombus \\
\hline 5 & Inamura et al. ${ }^{6}$ & 37 & $\mathrm{M}$ & NA & NA & $\mathrm{t}(6 ; 11)(\mathrm{p} 21.1 ; \mathrm{q} 12$ 13) & Dead after 120 months & Lung metastasis \\
\hline 6 & Peckova et al. ${ }^{7}$ & 77 & $\mathrm{~F}$ & 12 & pT3NxM1 & RT-PCR+break apart & Dead after 2,5 months & Adrenal gland and lung metastasis \\
\hline 7 & Smith et al. ${ }^{8}$ & 34 & $\mathrm{M}$ & 3 & pT1NxM1 & break apart probe & 96 months alive & Rib metastasis \\
\hline 8 & Lilleby et al. ${ }^{9}$ & 42 & $\mathrm{M}$ & NA & NA & break apart probe & 97 months alive & Vertebral and rib metastasis \\
\hline 9 & Argani et al..$^{10}$ & 61 & $\mathrm{~F}$ & 19 & pT4N0M1 & break apart probe & 18 months alive & Vaginal metastasis \\
\hline 10 & Present series (case 6) & 42 & $\mathrm{~F}$ & 10 & pT3aN0M1 & break apart probe & Dead after 46 months & Lung metastasis \\
\hline 11 & Present series (case 7) & 33 & M & 8 & pT3aNxM1 & break apart probe & 48 months alive & Perinephric and pelvic soft tissue tissue nodules \\
\hline
\end{tabular}

M: male, F: female, NA: not available, IVC: inferior vena cava.

${ }^{\mathrm{a}}$ FISH analysis in Smith et al ${ }^{8}$ 
Table 5 Nonaggressive $\mathrm{t}(6 ; 11)$ renal cell carcinomas

\begin{tabular}{|c|c|c|c|c|c|c|c|c|}
\hline Case & References & Age & Gender & Size $(\mathrm{cm})$ & Stage TNM & Karyotype/ FISH & Follow up & Notes \\
\hline 1 & Argani et al., ${ }^{2}$ Davis et al..$^{18}$ Argani et al. ${ }^{19}$ & 18 & M & 7 & pT1bNxMx & $\mathrm{t}(6 ; 11)(\mathrm{p} 21.1 ; \mathrm{q} 12)$ & 18 months & \\
\hline 2 & Argani et al., ${ }^{2}$ Argani et al., ${ }^{19}$ Martignoni et al. ${ }^{12}$ & 10 & M & 12 & pT2NxMx & $\mathrm{t}(6 ; 11)(\mathrm{p} 21.1 ; \mathrm{q} 12)$ & 26 months & \\
\hline 3 & Kuiper et al. ${ }^{20}$ & 42 & $\mathrm{~F}$ & NA & NA & $\mathrm{t}(6 ; 11)(\mathrm{p} 21 ; \mathrm{q} 13)$ & NA & \\
\hline 4 & Kuiper et al. ${ }^{20}$ & 17 & $\mathrm{~F}$ & NA & NA & $\mathrm{t}(6 ; 11)(\mathrm{p} 21 ; \mathrm{q} 13)$ & NA & \\
\hline 5 & Kuiper et al. ${ }^{20}$ Argani et al., ${ }^{19}$ Martignoni et al. ${ }^{12}$ & 14 & $\mathrm{~F}$ & 4.5 & pT1bNxMx & $\mathrm{t}(6 ; 11)(\mathrm{p} 21 ; \mathrm{q} 13)$ & NA & \\
\hline 6 & Davis et al. ${ }^{18}$ Argani et al. ${ }^{19}$ & 18 & $\mathrm{~F}$ & 2.8 & pT1aNxMx & $\begin{array}{l}\mathrm{t}(6 ; 11)(\mathrm{p} 21.1 ; \mathrm{q} 12)+\text { break } \\
\text { apart }\end{array}$ & 18 months & \\
\hline 7 & Argani et al., ${ }^{19}$ Martignoni et al. ${ }^{12}$ & 20 & $\mathrm{~F}$ & 9.5 & pT2NxMx & RT-PCR & 30 months & \\
\hline 8 & Argani et al., ${ }^{19}$ Geller et al. ${ }^{21}$ Martignoni et al. ${ }^{12}$ & 9 & $\mathrm{~F}$ & 2 & pT1aNxMx & RT-PCR & NA & $\begin{array}{l}\text { post chemotherapy } \\
\text { (nephroblastoma) }\end{array}$ \\
\hline 9 & Argani et al., ${ }^{19}$ Martignoni et al. ${ }^{12}$ & 33 & M & 6 & pT1bNxMx & RT-PCR & NA & \\
\hline 10 & Argani et al., ${ }^{33}$ Martignoni et al. ${ }^{12}$ & 6 & $\mathrm{~F}$ & 5 & pT1bNxMx & $\mathrm{t}(6 ; 11)(\mathrm{p} 21 ; \mathrm{q} 12)$ & 3 months & $\begin{array}{l}\text { post chemotherapy } \\
\text { (nephroblastoma) }\end{array}$ \\
\hline 11 & $\begin{array}{l}\text { Pecciarini et al. }{ }^{16} \text { Martignoni et al. }{ }^{12} \text { Petterson et al. }{ }^{17} \text { Present series } \\
\text { (case 2) }\end{array}$ & 54 & $\mathrm{~F}$ & 7 & pT1bNxMx & $\mathrm{t}(6 ; 11)(\mathrm{p} 21 ; \mathrm{q} 12)$ & 36 months & \\
\hline 12 & Camparo et al. ${ }^{3}$ & 34 & $\mathrm{~F}$ & 15 & pT2NoMo & $\mathrm{t}(6 ; 11)(\mathrm{p} 21 ; \mathrm{q} 13)$ & 50 months & \\
\hline 13 & Hora et al. ${ }^{22}$ Petterson et al. ${ }^{17}$ Peckova et al. ${ }^{7}$ & 22 & $\mathrm{M}$ & 4 & pT1bNxMx & NA & 40 months & \\
\hline 14 & Hora et al. ${ }^{22}$ Petterson et al. ${ }^{17}$ Peckova et al. ${ }^{7}$ & 24 & $\mathrm{~F}$ & 13.6 & pT2NxMx & $\mathrm{NA}^{\mathrm{a}}$ & 18 months & pregnant \\
\hline 15 & Hora et al. ${ }^{22}$ & 39 & $\mathrm{~F}$ & 1 & pT1aNxMx & NA & 13 months & \\
\hline 16 & Zhan et al. ${ }^{23}$ & 26 & M & 4.3 & pT1bNxMx & RT-PCR & 6 months & \\
\hline 17 & Malouf et al. ${ }^{24}$ & NA & NA & NA & NA & $\mathrm{NA}^{\mathrm{a}}$ & NA & \\
\hline 18 & Suarez Villa et al. ${ }^{25}$ & 22 & $\mathrm{M}$ & 10 & pT2NxM0 & $\mathrm{NA}^{\mathrm{a}}$ & NA & \\
\hline 19 & Argani et al. ${ }^{5}$ & 14 & $\mathrm{~F}$ & NA & NA & break apart probe & NA & \\
\hline 20 & Argani et al. ${ }^{5}$ & 37 & $\mathrm{M}$ & 4 & pT1aNxMx & break apart probe & NA & \\
\hline 21 & Argani et al., 5 & 3 & $\mathrm{~F}$ & 2 & pT1aNxMx & break apart probe & NA & \\
\hline 22 & Argani et al. ${ }^{5}$ & 58 & $\mathrm{~F}$ & 3 & pT1aNxMx & break apart probe & NA & \\
\hline 23 & Argani et al. ${ }^{5}$ & 34 & $\mathrm{M}$ & 1.8 & pT1aNxMx & break apart probe & NA & end stage kidney \\
\hline 24 & Argani et $a l^{5}$ & 25 & M & 15 & pT2NxMx & break apart probe & NA & \\
\hline 25 & Inamura et al. ${ }^{6}$ & 57 & $\mathrm{M}$ & 10.2 & pT2NxMx & $\mathrm{NA}^{\mathrm{a}}$ & 8 months & \\
\hline 26 & Inamura et al. ${ }^{6}$ & 47 & $\mathrm{M}$ & 3.2 & pT1aNxMx & $\mathrm{t}(6 ; 11)(\mathrm{p} 21.1 ; \mathrm{q} 12$ 13) & 12 months & \\
\hline 27 & Petterson et al. ${ }^{17}$ Peckova et al. ${ }^{7}$ Present series (case 3 ) & 20 & $\mathrm{~F}$ & 9.5 & pT2NxMx & $\mathrm{t}(6 ; 11)(\mathrm{p} 21 ; \mathrm{q} 12)$ & 60 months & \\
\hline 28 & Petterson et al. ${ }^{17}$ Peckova et al. ${ }^{7}$ & 54 & $\mathrm{~F}$ & 7 & pT1bNxMx & $\mathrm{t}(6 ; 11)(\mathrm{p} 21 ; \mathrm{q} 12)$ & 36 months & \\
\hline 29 & Rao et $a l^{26}$ & 31 & $\mathrm{~F}$ & 9 & pT2NxMx & break apart probe & 6 months & \\
\hline 30 & Rao et al. ${ }^{26}$ & 21 & $\mathrm{M}$ & 4 & pT1aNxMx & break apart probe & 22 months & \\
\hline 31 & Rao et al. ${ }^{26}$ & 37 & $\mathrm{~F}$ & 3 & pT1aNxMx & break apart probe & 34 months & \\
\hline 32 & Rao et al. ${ }^{26}$ & 36 & $\mathrm{~F}$ & 2.5 & pT1aNxMx & break apart probe & NA & \\
\hline 33 & Rao et al. ${ }^{26}$ & 30 & M & 9 & pT2NxMx & break apart probe & 31 months & \\
\hline 34 & Rao et $a .^{26}$ & 29 & $\mathrm{~F}$ & 4.5 & pT1bNxMx & break apart probe & 55 months & \\
\hline 35 & Rao et al. ${ }^{26}$ & 30 & $\mathrm{M}$ & 4 & pT1aNxMx & break apart probe & 36 months & \\
\hline 36 & Zhong et al. ${ }^{27}$ & 17 & $\mathrm{M}$ & 19 & pT2NxMx & $\mathrm{NA}^{\mathrm{a}}$ & NA & \\
\hline 37 & Rao et $a .^{28}$ & 68 & $\mathrm{M}$ & 2,5 & pT1aNxMx & break apart probe & 23 months & \\
\hline 38 & Peckova et al. ${ }^{7}$ & 15 & $\mathrm{M}$ & 10 & pT2NxMx & break apart probe & 12 months & \\
\hline 39 & Matsuura et al. ${ }^{29}$ & 40 & M & NA & NA & MALAT1(alpha)-TFEB & NA & \\
\hline 40 & Smith et al. ${ }^{8}$ & NA & NA & NA & NA & break apart probe & NA & \\
\hline 41 & Smith et al. ${ }^{8}$ & 44 & M & 7.8 & pT2NxMx & break apart probe & NA & \\
\hline 42 & Smith et al. ${ }^{8}$ & 9 & M & 4 & pT1aNxMx & break apart probe & NA & \\
\hline 43 & Smith et al. ${ }^{8}$ & 3 & $\mathrm{~F}$ & NA & NA & break apart probe & NA & \\
\hline 44 & Smith et al. ${ }^{8}$ & 23 & $\mathrm{M}$ & 10 & pT2NxMx & break apart probe & NA & \\
\hline 45 & Smith et al. ${ }^{8}$ & 9 & $\mathrm{~F}$ & 9 & pT2NxMx & break apart probe & NA & \\
\hline 46 & Smith et al. ${ }^{8}$ & 46 & $\mathrm{M}$ & 15 & pT2NxMx & break apart probe & NA & \\
\hline
\end{tabular}


material was noted in 1 of 7 tumors (case 3 ). A discontinuous pseudocapsule was present in 5 of 7 tumors and psammoma bodies were encountered in half tumors. Bony metaplasia and hyalinized stroma with thick-walled vessels were observed in two tumors. The cells typically showed nucleolar grade G2 and G3 by ISUP/WHO 2016. Tumor necrosis was absent and the proliferation rate was low with the exception of the two aggressive tumors in which focal necrosis and mitotic activity were found.

With respect to aggressive $t(6 ; 11)$ renal cell carcinoma, the present series as well as the review of the literature provides some useful information. Renal cell carcinoma with TFEB rearrangement displayed an aggressive behavior in roughly $17 \%$ of cases (11 of 64 ), occurring as larger masses (12 vs $7 \mathrm{~cm}$ ) in older patients (46 vs 30 years). It should be noted that hematogenous metastasis are more common than nodal metastasis, which was reported in two cases without molecular confirmation of $\mathrm{t}(6 ; 11)$ rearrangement.

Another important aspect of this study is the proper cutoff to define the occurrence of TFEB rearrangement in $\mathrm{t}(6 ; 11)$ renal cell carcinoma. Using standard criteria determined by scoring normal tissues for clinical assays, Argani et al. ${ }^{5}$ defined a positive FISH result in their clinical assay as when the fluorescent signals were separated by a signal diameter $>1$ in at least $15.8 \%$ neoplastic cells using standardized published methodology. In this study, we observed a high frequency $(74 \%)$ of split signals ( $\geq 2$ signals diameter) in $\mathrm{t}(6 ; 11)$ renal cell carcinomas, ranging from $61 \%$ to $94 \%$. Similar results have been published by Smith et al., reporting high frequency of split signals (range from $38-86 \%$, mean $69 \%$ ) in 10 cases. $^{8}$

Finally, we have evaluated the possible usefulness of CD68 as immunohistochemical marker to differentiate $\mathrm{t}(6 ; 11)$ renal cell carcinoma from pure epithelioid PEComa/epithelioid angiomyolipoma. Distinguishing those two entities is clinically important since mTOR inhibitors are a therapeutic option for the latter, ${ }^{34}$ and, in our experience, the differential diagnosis of $\mathrm{t}(6 ; 11)$ renal cell carcinoma with pure epithelioid PEComa/epithelioid angiomyolipoma is the most difficult. Both tumors are composed of medium and large cells with clear or faintly granular eosinophilic cytoplasm and enlarged nuclei usually with prominent nucleoli. As described in this study and previously reported, ${ }^{26,35} \mathrm{t}(6 ; 11)$ renal cell carcinoma may show hyalinized areas with thick-walled vessels mimicking the abnormal blood vessels in the angiomyolipoma. Moreover, the two entities share the immunohistochemical expression of melanocytic markers and cathepsin $\mathrm{K}$ and both are often negative for cytokeratin. ${ }^{36}$ Staining for PAX8 has been demonstrated a useful tool in this challenging diagnosis. In this study we found that all but one FISH-confirmed $\mathrm{t}(6 ; 11)$ renal cell carcinoma were positive for PAX8 and 7 pure epithelioid 
PEComa/epithelioid angiomyolipomas were consistently negative. As we previously reported, ${ }^{14}$ either CD68 (PG-M1) or CD68 (KP1) labeled pure epithelioid PEComa/epithelioid angiomyolipomas. On the other hand, all seven $\mathrm{t}(6 ; 11)$ renal cell carcinomas were completely negative for CD68 (PG-M1) but positive for CD68 (KP1), supporting the usefulness of CD68 (PG-M1) along with PAX8 in distinguishing $t$ $(6 ; 11)$ renal cell carcinoma from pure epithelioid PEComa/epithelioid angiomyolipoma. The absence of CD68 (PG-M1) was surprising in that TFEB is known to be a master regulator of lysosomal proteins expression, and it thought to drive expression of cathepsin $\mathrm{K}$ in the $\mathrm{t}(6 ; 11)$ renal cell carcinoma. A possible explanation could be attributed to the different epitopes recognized by the two different clones; the epitope recognized by CD68 (PG-M1) might be lost or masked during carcinogenesis.

In summary, in this study we present the clinical, morphological and molecular features of seven $\mathrm{t}(6 ; 11)$ renal cell carcinomas, two cases developing metastasis which were histologically confirmed. We report the high frequency of split signals by FISH in tumors with $\mathrm{t}(6 ; 11)$ chromosomal rearrangement and the occurrence of TFEB gene copy number increases in the aggressive cases. Finally, we demonstrate the usefulness of CD68 (PG-M1) immunohistochemical staining in distinguishing $\mathrm{t}(6 ; 11)$ renal cell carcinoma from pure epithelioid PEComa/epithelioid angiomyolipoma.

\section{Disclosure/conflict of interest}

The authors declare no conflict of interest.

\section{References}

1 Argani P, Cheville J, Ladanyi MMiT family translocation renal cell carcinomaInMoch $\mathrm{H}$, Humprey PA, Ulbright TM, Reuter VE (eds). WHO Classification of Tumours of the Urinary System and Male Genital Organs. International Agency for Research on Cancer: Lyon, France, 2016, pp 40-41.

2 Argani P, Hawkins A, Griffin CA, et al. A distinctive pediatric renal neoplasm characterized by epithelioid morphology, basement membrane production, focal HMB45 immunoreactivity, and t(6;11)(p21.1;q12) chromosome translocation. Am J Pathol 2001;158: 2089-2096.

3 Camparo P, Vasiliu V, Molinie V, et al. Renal translocation carcinomas: clinicopathologic, immunohistochemical, and gene expression profiling analysis of 31 cases with a review of the literature. Am J Surg Pathol 2008;32:656-670.

4 Ishihara A, Yamashita $\mathrm{Y}$, Takamori $\mathrm{H}$, et al. Renal carcinoma with $(6 ; 11)(p 21 ; q 12)$ translocation: report of an adult case. Pathol Int 2011;61:539-545.

5 Argani P, Yonescu R, Morsberger L, et al. Molecular confirmation of $\mathrm{t}(6 ; 11)(\mathrm{p} 21 ; \mathrm{q} 12)$ renal cell carcinoma in archival paraffin-embedded material using a breakapart TFEB FISH assay expands its clinicopathologic spectrum. Am J Surg Pathol 2012;36:1516-1526.
6 Inamura K, Fujiwara M, Togashi Y, et al. Diverse fusion patterns and heterogeneous clinicopathologic features of renal cell carcinoma with $\mathrm{t}(6 ; 11)$ translocation. Am J Surg Pathol 2012;36:35-42.

7 Peckova K, Vanecek T, Martinek P, et al. Aggressive and nonaggressive translocation $t(6 ; 11)$ renal cell carcinoma: comparative study of 6 cases and review of the literature. Ann Diagn Pathol 2014;18:351-357.

8 Smith NE, Illei PB, Allaf $M$, et al. $\mathrm{t}(6 ; 11)$ renal cell carcinoma (RCC): expanded immunohistochemical profile emphasizing novel RCC markers and report of 10 new genetically confirmed cases. Am J Surg Pathol 2014;38:604-614.

9 Lilleby W, Vlatkovic L, Meza-Zepeda LA, et al. Translocational renal cell carcinoma $(\mathrm{t}(6 ; 11)(\mathrm{p} 21 ; \mathrm{q} 12)$ with transcription factor EB (TFEB) amplification and an integrated precision approach: a case report. J Med Case Rep 2015;9:281.

10 Argani P, Reuter VE, Zhang L, et al. TFEB-amplified renal cell carcinomas: an aggressive molecular subset demonstrating variable melanocytic marker expression and morphologic heterogeneity. Am J Surg Pathol 2016;40:1484-1495.

11 Argani P. MiT family translocation renal cell carcinoma. Semin Diagn Pathol 2015;32:103-113.

12 Martignoni G, Pea M, Gobbo S, et al. Cathepsin-K immunoreactivity distinguishes MiTF/TFE family renal translocation carcinomas from other renal carcinomas. Mod Pathol 2009;22:1016-1022.

13 Brimo F, Robinson B, Guo C, et al. Renal epithelioid angiomyolipoma with atypia: a series of 40 cases with emphasis on clinicopathologic prognostic indicators of malignancy. Am J Surg Pathol 2010;34: $715-722$.

14 Martignoni G, Bonetti F, Chilosi M, et al. Cathepsin K expression in the spectrum of perivascular epithelioid cell (PEC) lesions of the kidney. Mod Pathol 2012;25: 100-111.

15 Sardiello M, Palmieri M, di Ronza A, et al. A gene network regulating lysosomal biogenesis and function. Science 2009;325:473-477.

16 Pecciarini L, Cangi MG, Lo Cunsolo C, et al. Characterization of $\mathrm{t}(6 ; 11)(\mathrm{p} 21 ; \mathrm{q} 12)$ in a renal-cell carcinoma of an adult patient. Genes Chromosomes Cancer 2007;46: 419-426.

17 Petersson F, Vanecek T, Michal M, et al. A distinctive translocation carcinoma of the kidney; 'rosette forming,' t(6;11), HMB45-positive renal tumor: a histomorphologic, immunohistochemical, ultrastructural, and molecular genetic study of 4 cases. Hum Pathol 2012;43:726-736.

18 Davis IJ, Hsi BL, Arroyo JD, et al. Cloning of an AlphaTFEB fusion in renal tumors harboring the $t(6 ; 11)(p 21$; q13) chromosome translocation. Proc Natl Acad Sci U S A 2003;100:6051-6056.

19 Argani P, Ladanyi M. Translocation carcinomas of the kidney. Clin Lab Med 2005;25:363-378.

20 Kuiper RP, Schepens M, Thijssen J, et al. Upregulation of the transcription factor TFEB in $t(6 ; 11)(p 21 ; q 13)-$ positive renal cell carcinomas due to promoter substitution. Hum Mol Genet 2003;12:1661-1669.

21 Geller JI, Argani P, Adeniran A, et al. Translocation renal cell carcinoma: lack of negative impact due to lymph node spread. Cancer 2008;112: 1607-1616.

22 Hora M, Hes O, Urge T, et al. A distinctive translocation carcinoma of the kidney ['rosette-like forming,' t(6;11), 
HMB45-positive renal tumor]. Int Urol Nephrol 2009;41:553-557.

23 Zhan HQ, Wang CF, Zhu XZ, et al. Renal cell carcinoma with $\mathrm{t}(6 ; 11)$ translocation: a patient case with a novel Alpha-TFEB fusion point. J Clin Oncol 2010;28:e709-e713.

24 Malouf GG, Camparo P, Molinie V, et al. Transcription factor E3 and transcription factor EB renal cell carcinomas: clinical features, biological behavior and prognostic factors. J Urol 2011;185:24-29.

25 Suarez-Vilela D, Izquierdo-Garcia F, Mendez-Alvarez JR, et al. Renal translocation carcinoma with expression of TFEB: presentation of a case with distinctive histological and immunohistochemical features. Int J Surg Pathol 2011;19:506-509.

26 Rao Q, Liu B, Cheng L, et al. Renal cell carcinomas with $\mathrm{t}(6 ; 11)(\mathrm{p} 21 ; \mathrm{q} 12)$ : A clinicopathologic study emphasizing unusual morphology, novel alpha-TFEB gene fusion point, immunobiomarkers, and ultrastructural features, as well as detection of the gene fusion by fluorescence in situ hybridization. Am J Surg Pathol 2012;36:1327-1338.

27 Zhong M, De Angelo P, Osborne L, et al. Translocation renal cell carcinomas in adults: a single-institution experience. Am J Surg Pathol 2012;36:654-662.

28 Rao Q, Zhang XM, Tu P, et al. Renal cell carcinomas with $\mathrm{t}(6 ; 11)(\mathrm{p} 21 ; \mathrm{q} 12)$ presenting with tubulocystic renal cell carcinoma-like features. Int J Clin Exp Pathol 2013;6:1452-1457.
29 Matsuura K, Inoue T, Kai T, et al. Molecular analysis of a case of renal cell carcinoma with $\mathrm{t}(6 ; 11)(\mathrm{p} 21 ; \mathrm{q} 12)$ reveals a link to a lysosome-like structure. Histopathology 2014;64:306-309.

30 Arneja SK, Gujar N. Renal cell carcinoma with t(6:11) (p21;q12). A case report highlighting distinctive immunohistologic features of this rare tumor. Int J Surg Case Rep 2015;7C:16-19.

31 Williamson SR, Grignon DJ, Cheng L, et al. Renal cell carcinoma with chromosome $6 \mathrm{p}$ amplification including the TFEB gene: a novel mechanism of tumor pathogenesis? Am J Surg Pathol 2016;41:287-298.

32 Gupta S, Johnson SH, Vasmatzis G, et al. TFEB-VEGFA (6p21.1) co-amplified renal cell carcinoma: a distinct entity with potential implications for clinical management. Mod Pathol 2017;30:998-1012.

33 Argani P, Lae M, Ballard ET, et al. Translocation carcinomas of the kidney after chemotherapy in childhood. J Clin Oncol 2006;24:1529-1534.

34 Wolff N, Kabbani W, Bradley T, et al. Sirolimus and temsirolimus for epithelioid angiomyolipoma. J Clin Oncol 2010;28:e65-e68.

35 Williamson SR, Eble JN, Palanisamy N. Sclerosing TFEB-rearrangement renal cell carcinoma: a recurring histologic pattern. Hum Pathol 2017;62:175-179.

36 Martignoni G, Pea M, Zampini C, et al. PEComas of the kidney and of the genitourinary tract. Semin Diagn Pathol 2015;32:140-159. 